\title{
De prostituta a trabajadora sexual: legitimación de la prostitución a través del relato cinematográfico
}

\author{
From prostitute to sex worker: The legitimation of \\ prostitution through cinematographic narratives
}

Juana Gallego

Recibido: 02/10/2017

Aceptado: 22/04/2018

\section{RESUMEN}

Este artículo hace un recorrido por la representación que el relato cinematográfico ha propuesto sobre la prostitución, desde sus inicios hasta la actualidad. Del sinnúmero de roles que las actrices pueden representar en el cine, el de prostituta ha sido uno de los más frecuentes. Este texto reflexiona sobre la evolución producida en el tratamiento de la figura de la prostituta en los relatos cinematográficos, a la vez que se pregunta si este cambio ha afectado a la percepción que la sociedad ha ido interiorizando sobre la prostitución. El artículo parte de la premisa de que realidad y ficción se interrelacionan y se retroalimentan mutuamente, de tal manera que nuestro imaginario colectivo se nutre de los relatos que consumimos, a la vez que los relatos se alimentan de los cambios que se producen en la sociedad. Se defiende, por tanto, que el cine es un vehículo que contribuye poderosamente a modelar la percepción que la sociedad tiene de los fenómenos sociales y que, en el caso de la prostitución, ha contribuido a su legitimación.

Palabras clave: prostitución, cine, relato cinematográfico, trabajadora sexual, legitimación, prostituta, percepción sobre la prostitución

\begin{abstract}
This article focuses on the way cinematographic history depicts the prostitution phenomenon from the beginning to present day. Among all the roles that actresses can play in cinema, prostitutes have been those most represented by women. This article reflects the evolution experienced by prostitution in films and suggests whether this evolution has affected the society's perception towards the prostitute's figure. The article defends that fiction and reality are interrelated. Our collective imagination nourishes from the stories we consume, and at the same time the stories feed the changes experienced by society. The article defends that the film industry is a very powerful tool to give shape to the perception that society has about social phenomena, and that in the case of prostitution in particular it has contributed to its legitimation.
\end{abstract}

Juana Gallego es profesora de periodismo en la Universitat Autònoma de Barcelona (UAB), directora del Observatorio para la Igualdad, y codirectora del Máster de Género y Comunicación. Correo electrónico: Joana.Gallego@uab.cat. ID: https:/ / orcid.org/0000-0001-6300-2095

Cómo citar este artículo: Gallego, J. (2018). De prostituta a trabajadora sexual: legitimación de la prostitución a través del relato cinematográfico. Atlánticas. Revista Internacional de Estudios Feministas, 3 (1), 33-61 doi: http://dx.doi.org/10.17979/arief.2018.3.1.3079 
De prostituta a trabajadora sexual: legitimación de la prostitución a través del relato cinematográfico

Keywords: prostitution, prostitute, cinema, cinematographic history, sex worker, cinematic prostitute, legitimation of prostitution. 


\section{INTRODUCCIÓN}

A finales de diciembre de 2016 apareció en la prensa una noticia que daba cuenta de la bajada en la edad de los clientes de la prostitución. Basándose en datos aportados por la policía, diversos medios se hicieron eco de este hecho (entre otros El País, 24-12-2016) y de la preocupación consiguiente ante el uso lúdico y festivo que de la prostitución estaban haciendo los jóvenes en sus prácticas sexuales. Una tendencia que ya se había observado unos años antes. Que los jóvenes rondando los 20 años o menos sigan recurriendo al sexo de pago como ya hacían sus abuelos y sus padres (y han hecho muchos hombres a lo largo de la historia) debería hacernos reflexionar sobre la educación, el tipo de valores que se siguen transmitiendo, $\mathrm{y}$, en especial sobre la persistencia de la concepción patriarcal que se tiene del sexo y la sexualidad.

De totas formas creo que se puede afirmar que en la sociedad española ha habido un cambio importante en este sentido, ya que la estricta doble moral que se mantuvo durante tanto tiempo para juzgar los comportamientos sexuales de hombres y mujeres se ha desvanecido, al menos en parte y en importantes zonas del planeta, aunque todavía no exista una total equiparación a la hora de valorar la conducta sexual de varones y mujeres. Cómo se producen los cambios, de qué manera una sociedad fuertemente tradicionalista en su valoración de la moral sexual puede experimentar giros ideológicos tan acusados, cómo y por qué se impone una nueva consideración de sus prácticas sexuales es lo que vamos a intentar desarrollar en este capítulo, con especial atención al análisis de los discursos cinematográficos, que proporcionan el indispensable flujo nutricional a los imaginarios colectivos; esta nueva percepción va a revertir en cambios en la realidad que, a su vez, cristalizarán en nuevas propuestas discursivas, y así sucesivamente. Este texto no está planteado como investigación empírica, sino más bien como un ensayo o reflexión sobre el tema, razón por la cual no se ofrece la estructura convencional ni metodológica habitual. Como no está planteado como texto de investigación, sino de reflexión, es posible que se echen en falta referencias o aportaciones de relieve que se hayan hecho anteriormente. Lo aquí escrito no aspira a novedad alguna, sino a ofrecer algunas ideas y reflexiones que posiblemente otros hayan hecho antes y mejor que yo sobre la representación de la figura de la prostituta en el relato cinematográfico. 
Estoy persuadida de que muchas personas que se comprometieron en la lucha por los derechos de las prostitutas -incluidas algunas asociaciones feministashabían imaginado que la simple consecución de una sociedad más igualitaria que la que habíamos heredado de tiempos pasados iba a traducirse en un abandono paulatino de ciertas prácticas, y que su acción estaba encaminada a combatir el estigma asociado a esta actividad y a la dignificación de las mujeres que se encontraban en situación de prostitución. No estoy tan segura de que entrara en sus cálculos que los jóvenes se convirtieran en usuarios, proporcionando nuevos bríos al negocio. Y tampoco estoy muy segura de que en realidad estos grupos estuvieran realmente interesados en mantener indefinidamente este modelo de relación sexual mercantilizado. Si realmente la prostitución es un trabajo como otro cualquiera debería universalizarse (es decir que cualquiera pudiera dedicarse a ello, hombres o mujeres), debería establecerse un contrato entre usuario-prestador del servicio, posibilidad de reclamación en caso de incumplimiento entre otras muchas cuestiones que habría que contemplar para que la actividad dejara de formar parte de la economía sumergida y entrara en el catálogo de las salidas laborales a las que cualquiera pudiera acogerse. A este respecto Beatriz Gimeno (2012), Ana de Miguel (2015) o Rosa Cobo (2017) han dado suficientes argumentos para demostrar que la prostitución no es un trabajo como otro cualquiera.

Casi ningún colectivo relacionado con la prostitución tiene entre sus objetivos la reglamentación (incluso Hetaira, la asociación que más se ha destacado en la defensa de las prostitutas ha matizado en ocasiones que no reclama la regularización sino la normalización de la prostitución mediante los derechos colectivos), empezando porque se encuentran con la oposición de la mayoría de las prostitutas, que no parece que estén por la labor de inscribirse como tales en un epígrafe específico que se creara ad hoc. La mera dedicación a la prostitución ya implica un cierto secretismo y ocultación (a la familia, a los amigos, a los demás). Ponerse la etiqueta de trabajadora del sexo todavía encuentra la resistencia y la renuencia de las mujeres en esta situación. La mayoría de las prostitutas y colectivos que las apoyan lo que más bien reclaman son los derechos sociales (asistencia sanitaria, cotización a la seguridad social, pensión de jubilación, etc.) además de respeto y dignificación. Sin embargo, hace tiempo que las mujeres en situación de prostitución pueden ser autónomas o formar cooperativas, así como cotizar a la seguridad social, y que por tanto la 
regularización no es necesaria y por tanto forma parte de un debate falso ${ }^{1}$. Los únicos interesados realmente en una legalización total son la patronal de los clubs de alterne (ANELA) que consideran su actividad como un sector económico más junto a la hostelería (sector 12) ya que ven este negocio como una oferta de ocio como otra cualquiera (El Periódico de Catalunya, 29-11-2002).

\subsection{Entre el estigma y la dignificación}

Luís Sánchez y Livia García, en el trabajo Los españoles y la sexualidad en el siglo XXI que realizaron para el CIS en los años 2008 y 2009 parten de la consideración de que la sexualidad comprende un conjunto de comportamientos socialmente construidos que han de contextualizarse necesariamente en un entorno cultural posmoderno en el que estas conductas han quedado mayoritariamente desligadas de aquellas llevadas a cabo con la finalidad de la procreación (CIS, 2014), objetivo que había sido el fin último tradicional defendido, entre otros, por la religión católica, pero también por el poder político, ideológico y cultural anterior a la instauración de la democracia en 1976. En este trabajo se presenta un muy pormenorizado estado de la cuestión sobre la percepción de la ciudadanía respecto de la sexualidad. Este libro incluye, como no podía ser de otra manera, un capítulo dedicado a "El sexo como negocio" donde se afirma que el 77\% de los españoles considera que la prostitución es inevitable y que debería legalizarse. Otros trabajos más recientes coinciden en la misma idea (Rodríguez Villoria, 2015).

¿Realmente la sociedad española empieza a considerar la prostitución como un trabajo más? ¿O es solo una actitud que podría encuadrarse entre las declaraciones políticamente correctas para no parecer anticuado? ¿Quienes definen la prostitución como trabajo sexual, lo aceptarían para sí (o para sus hijas e hijos o familiares) para afrontar momentos económicos adversos o como simple salida laboral? Si se ha producido este cambio en la percepción social de una actividad tan denigrada y estigmatizada ¿Qué factores han sido determinantes para producir este cambio? ¿Como ha cambiado, si lo ha hecho, el imaginario colectivo sobre la prostituta? ¿Como ha evolucionado el discurso sobre este tema a través del cine y otros productos culturales?

\footnotetext{
${ }^{1}$ Para ver la evolución política y social de los debates sobre la prostitución en España véase Celia Valiente "State feminism and central state debates on prostitution in post-authoritarian Spain" in The Politics of prostitution, Joyce Outshoorn (ed.) Cambridge University Press, 2004, pp. 205-224.
} 
Sabemos que los problemas sociales no surgen por generación espontánea, sino que tienen un largo recorrido desde que se empiezan a gestar hasta que son reconocidos y aceptados como tales. Algunos autores sostienen que lo problemas sociales no existen por sí mismos, sino que son producto de un proceso de definición colectiva que ocurre cuando un número significativo de personas consideran ciertas situaciones sociales como no deseadas y tienen el suficiente poder como para transmitir esa percepción a otros sectores (Bosch y Ferrer, 2000). En este sentido, la acción coordinada de los medios de comunicación, así como el reiterado abordaje del tema como motivo televisivo o cinematográfico puede hacer aflorar el problema, coadyuvar a hacer extensiva una nueva percepción del fenómeno o presentar nuevas maneras de interpretarlo. Sin duda no hay un único factor que contribuya a la manera en que la sociedad percibe e interpreta las diferentes prácticas sociales instaladas en la cotidianidad de un grupo humano determinado, aunque podemos aventurar que la frecuencia y la perspectiva con la que se aborden en los medios, las opiniones que sean mantenidas por columnistas o colaboradores mediáticos, la acción de campañas institucionales o privadas que se pongan en circulación, así como el impacto que puedan tener los nuevos relatos simbólicos que sobre esas nuevas problemáticas se elaboren necesariamente han de contribuir a la formación de estados de opinión y al cambio, en su caso, del parecer en ámbitos más o menos amplios de la población.

Tampoco son ajenos a la mutación en el estado de opinión sobre un determinado tema los discursos ideológicos y políticos que se sostengan en un momento histórico concreto: el neoliberalismo en lo económico, el relativismo en lo cultural y la entronización del concepto de libertad individual propio de las democracias liberales son las tres patas sobre las que descansa nuestro sistema de pensamiento actual, que no solo incluye este tema, sino otros actualmente tan controvertidos como podría ser la maternidad subrogada.

La principal batalla para influir en la opinión pública es el "marco discursivo" en que se sitúan los problemas sociales. Y la herramienta fundamental, junto con otros dispositivos simbólicos, es el lenguaje. Es decir, cómo se denomina la nueva práctica o problema ante el que nos encontramos. No es lo mismo hablar de "prostituta" que de "trabajadora sexual", de la misma manera que no tiene la misma connotación decir "vientres de alquiler" a lo que los partidarios de esta modalidad de gestación llaman "maternidad subrogada" o incluso "gestación 
subrogada", eliminando de un plumazo la referencia a la maternidad que, con deliberado propósito, desaparece para dar paso solo a la "gestación". Términos lingüísticos que tienen una poderosa capacidad para transformar la percepción social de los fenómenos. Este cambio en el enfoque discursivo es al que Celia Amorós denomina "la resignificación de los términos heredados" (Amorós, 2005). Esta autora habla de la resignificación voluntarista, que no siempre tiene éxito. Para que esa resignificación se estabilice y tenga éxito - y no siempre de forma permanente- es necesario que un grupo organizado se proponga la reasignación de significado como objetivo político y se lance a reproducirlo e implementarlo de todas las formas posibles, fundamentalmente a través de los medios de comunicación y otras formas simbólicas (como el caso del cine, que analizaremos en este capítulo). A un término que tiene unas connotaciones peyorativas (prostituta, vientre de alquiler) se le asigna una nueva denominación que lo dignifica (trabajadora sexual, gestación subrogada) haciendo que parezca más neutro y aséptico, y por ende más aceptable por la ciudadanía. El test que demuestra que la resignificación ha tenido éxito, según Amorós, es que el valor resignificado se universalice y no sea asignado sólo a un sexo/género.

\subsection{La prostitución en el relato cinematográfico}

El cambio social, si se produce, requiere de prolongados y continuados procesos que, a veces imperceptiblemente, van transformando el estado mental de la ciudadanía, primero, y solo en muy segundo lugar, y no siempre, provoca cambios estructurales. Los cambios sociales nunca suelen ser bruscos, y cuando lo son, no necesariamente producen un vuelco en el sistema simbólico formado por creencias, valores, tradiciones, costumbres, ideas y todo el entramado cultural que sostiene la parte inmaterial de los diferentes grupos humanos. Una revolución puede imponer un nuevo sistema de producción, un nuevo marco jurídico, una reforma legal pero no garantiza que el cuerpo social modifique sustancialmente las creencias culturales y simbólicas que lo han sostenido, lo que en términos marxistas se entendía como la superestructura ideológica. La sociedad tiende a la estabilidad material y cultural, y por ello suele ser renuente a introducir cambios significativos que trastoquen el estado de cosas conocido.

Sin embargo, el cambio social puede ocurrir por la labor continuada y conjunta de grupos concretos que reclaman reformas políticas o sociales en el nivel material, hecho que puede verse reforzado por la aparición de discursos 
simbólicos que, sincrónica y diacrónicamente, han ido recogiendo $\mathrm{y}$ amplificando esos nuevos valores que los grupos reivindicativos tratan de obtener. En esa conjunción de la acción social con la acción cultural es donde debemos situar los discursos que sobre la prostitución ha ido proponiendo el relato cinematográfico o televisivo desde sus inicios hasta la actualidad.

Si ha habido una actividad o práctica constante y reiterada en la sociedad a lo largo de los siglos esta ha sido la prostitución femenina. No es de extrañar, por tanto, que este tema haya sido uno de los más recurrentes a la hora de elaborar relatos, historias, cuentos, narraciones que han tenido como protagonistas a esas mujeres que, voluntaria o involuntariamente, se han situado en los márgenes del epicentro social. La prostituta es sin duda alguna la figura o "motivo" que la mayoría de las actrices ha representado en el cine. La gran mayoría de los filmes, en un momento $\mathrm{u}$ otro, ya sea de manera central, secundaria $\mathrm{o}$ tangencial, han introducido ni que sea fugazmente, alguna referencia a la prostitución. En el análisis que hace Pilar Aguilar en un capitulo sobre la representación de las mujeres en las películas españolas se pone de relieve que en los 26 filmes españoles más vistos entre 2000 y 2006 el 30,8\% incluyen personajes que van de putas (Aguilar, 2010) dato que ya se había puesto de manifiesto en una aportación anterior (Aguilar,1998) según la cual la prostitución era la actividad más recurrente desempeñada en el cine por las mujeres, muy por encima de cualquier otra profesión u oficio.

Y es que, como ya advirtiera Simone de Beauvoir la prostitución es el correlato del matrimonio, el reverso de la moneda (Beauvoir, 1948). Tanto uno como la otra son dos mecanismos patriarcales de control (dispositivo, en términos de Foucault, 1976) instituidos para sujetar la sexualidad femenina. La semejanza entre el matrimonio y la prostitución como las dos caras de la misma moneda la pone de relieve con lúcida anticipación una joven prostituta llamada Mickey en la película La calle de la vergüenza (1956) del japonés Kenji Mizoguchi. En este pionero film vemos un grupo de prostitutas preocupadas por su futuro cuando cierre el burdel La Aldea, donde trabajan. Una se queja de que su marido la explotaba más que los dueños del burdel, a lo que Mickey, refiriéndose al matrimonio, dice: "Es que yo no veo la diferencia: casarse es como venderse, solo que nosotras nos vendemos por períodos más cortos". Aguda reflexión que pone en el mismo plano las servidumbres sexuales que conlleva el matrimonio con las propias de la prostitución: la diferencia es que el primero 
otorga e incluye la honorabilidad y la segunda el desprecio y el estigma.

Porque la primera división que se establece entre las mujeres no es de clase, de raza, de edad o de procedencia sino de orden moral: las mujeres decentes o respetables y las que no lo son (Campbell, 2006). Dos categorías antagónicas vitalicias a las cuales no se puede pertenecer simultáneamente: o estás en el grupo de las respetables o en el de las indecentes; perteneces a un solo hombre o perteneces a todos y a ninguno, clasificación que los hombres no han tenido que experimentar nunca. No vamos a ahondar en las raíces históricas, políticas o sociales de esta clasificación moral, pues nos apartaría demasiado de los propósitos de este capítulo, baste con señalar que esta división ha sido un potente instrumento de control para constreñir la libertad sexual de las mujeres, que automáticamente entraban en la consideración de perdidas o caídas si insinuaban ni que fuese mínimamente cierta liberalidad en las costumbres. La permanente amenaza de perder la reputación o virtud coartaba cualquier incipiente gesto encaminado a mostrar deseo sexual fuera del estricto marco del matrimonio y, a veces, ni siquiera en él. Infinidad de películas nos han mostrado el recto proceder que tenía que mantener una joven si quería ser respetada: la madre de la película Esplendor en la hierba (1961) le da un soberbio discurso a su hija, la inocente Wilma Deanie (Nathalie Wood) cuando esta le pregunta si es tan malo sentir deseo por un chico: "Ninguna chica decente lo siente. Una decente, no" le dice tajante. Y luego prosigue:

"Un hombre no respeta a una chica que le permita llegar hasta el final. Quieren a una mujer decente por esposa. (...) Tu padre no me puso la mano encima hasta que nos casamos, y luego yo me dejé porque es la obligación de toda esposa. Una mujer no disfruta esas cosas como un hombre, solo deja que su marido se acerque para tener hijos". (Fragmento de Esplendor en la hierba (1961)".

He aquí, mejor expresado imposible, el discurso transmitido de madres a hijas sobre la respetabilidad y la decencia. Ni que decir tiene que esta manera abrupta de inhibir el deseo trunca para siempre la espontaneidad amorosa y la posibilidad de desarrollar una vida sentimental satisfactoria de cualquier joven. Esta idea de la sexualidad como algo pecaminoso, moralmente reprobable, que había que reprimir hasta la consumación del matrimonio es la que han recibido todas las generaciones de mujeres hasta hace unas décadas, y aún hoy la pátina 
moral sigue vigente abiertamente en muchas culturas, y de forma solapada y latente en la mayoría de las sociedades, incluidas las consideradas más avanzadas, pese a la aparente entronización del sexo y la liberalidad de las costumbres.

El cine, con su capacidad para proponer imaginarios y modelos, ha dado infinitas muestras de la imposibilidad para una mujer de vivir el deseo en libertad. La mayor parte de las veces esos impulsos eran sancionados o bien con el desprecio público, el repudio social, la enfermedad o la muerte. Gloria (Elizabeth Taylor) es una joven encantadora que desea dar curso libre a su pasión en Butterflied 8 (Una mujer marcada, 1960), como haría cualquier hombre sin ver comprometida su reputación. Sin embargo, ella no solo es sancionada por su madre y por la sociedad, sino por sí misma ya que acaba suicidándose: "El coronol Hartley -dice refiriéndose a un hombre que la inició en el sexo cuando tenía 13 años- me enseñó cosas que una mujer nunca debería aprender". Por muy libidinosas que fueran, nos preguntamos qué cosas serían esas que las mujeres no deberían saber. ¿Hay prácticas sexuales que las mujeres deberían ignorar? ¿Conocer las técnicas amatorias es ya de por sí indecente?

En cambio, para la prostituta cuantas más técnicas sexuales domina y con cuanta mayor efectividad puede satisfacer el placer masculino más valorada es. Todas estas técnicas y y el dominio de los más audaces procedimientos sexuales son precisamente los aspectos que distinguen a ese otro tipo de mujer que se opone a la decente: la prostituta es más valiosa cuanto más desinhibida se muestre: "Nosotras hacemos lo que no puedes hacer con tu mujer" (extraído de un anuncio de prostitución) lo que significa que aún hoy hay unos estrictos límites entre lo que se considera una sexualidad honesta y otra execrable; una sexualidad que las mujeres respetables pueden practicar sin que ni ellas ni sus maridos-novios-amantes puedan sentir como denigrante y otra sexualidad altamente deseable por esos mismos hombres que pueden dar rienda suelta a sus impulsos sin el sentimiento de estar sometiendo a sus parejas a prácticas denigratorias: En El Gatopardo (1963) tenemos esta dicotomía entre las prácticas autorizadas que podía hacer una mujer y las que llevaba a cabo la prostituta. El Príncipe de Salina, Fabrizio Corbera, protesta de esta manera cuando tras haber ido de putas la noche anterior es amonestado por el sacerdote-consejero, que le conmina a confesarse: "¿Qué queréis, monseñor? Soy un hombre fuerte. No puedo conformarme con una mujer que hace el signo de 
la cruz antes de cada abrazo. Siete hijos he tenido, siete. Y sabéis lo que os digo, padre, no le he visto a mi mujer más allá del tobillo. ¿Es justo eso? ella es la pecadora". Al mismo tiempo, el ojito derecho del Príncipe, el joven Tancredi (Alain Delon) le dice a su amada, la bella Angélica: "Te deseo, pero no te poseeré hasta que seas mi esposa".

En la divertida y emotiva El apartamento (1960) vemos reflejadas las costumbres sexuales de la mayor parte de los hombres casados que, sin detrimento de su respetabilidad, suelen llevar una doble vida amorosa: una mujer decente en casa para cuidar el hogar y los hijos; una joven casquivana, fija o esporádica, para satisfacer sus deseos eróticos. En La colmena (1982) vemos cómo los hombres honestos visitan el burdel de manera natural, algunos esporádicamente, otros para guarecerse de las inclemencias del tiempo. La prostitución ha sido, en muchos sentidos, la escuela de iniciación sexual para el aprendizaje de la masculinidad, y de ello tenemos numerosas muestras fílmicas.

Sexo prohibido y desconocimiento para las mujeres. Sexo autorizado y experiencia para los hombres. Esa ha sido la tradición patriarcal, y aunque hoy día las cosas han cambiado y las mujeres ya no son juzgadas por el uso que hagan de su sexualidad -o lo sean de otro modo, pero esa es otra historia- aún quedan vestigios de estas creencias y podemos verlas materializarse en el trato despreciativo con que se alude a las mujeres en muchas series de televisión (en las aclamadas The Wire o Los Soprano, sin ir más lejos) y no precisamente porque sean prostitutas: zorras, cerdas, putas, chupapollas, furcia, fulana, guarra, perra y otros apelativos semejantes.

\subsubsection{La prostituta víctima}

La mayor parte de los relatos cinematográficos que se han realizado sobre la prostitución han presentado a la prostituta como una víctima de las circunstancias. Esto fue así durante toda la primera mitad del siglo XX: desde las primeras películas mudas que popularizaron el concepto de trata de blancas hasta las que se realizaron en los años 60. Las mujeres caídas lo habían sido por alguna causa que se especificaba en el relato: han sido abandonadas por sus familias, son huérfanas, se han quedado sin otra forma de subsistir, han sido engañadas por un hombre y por tanto perdido la respetabilidad. Desde la muda Traffic in Souls (1913) hasta Pretty Woman (1990) en la práctica totalidad 
de las películas que tienen una prostituta como protagonista se suele explicar por qué se dedica a esta actividad, casi todas son huérfanas o provienen de familias desestructuradas que las han abandonado: La Thymiane de Diary of a lost girl (1929), Anne Christie (1930), la Frankie de El delator (1935) la Myra de El puente de Waterloo (1940), la Anna de El bosque de los placeres (1947), la Dolores que da título a La copla (1947), la María de Trotacalles (1951) la tierna Cabiria (1956), la Callie de Duelo en el barro (1958), la sorprendida Maribel y la extraña familia (1960), la Bianca de La Viaccia (1961), la dulce Stella de Accatone (1961), la Kitty de La Gata Negra (1962), la infeliz Berta de Bubu de Montparnasse (1970) la pizpireta Iris de Taxi Driver (1976), la desamparada Tralala de Última salida Brooklyn (1989), la torturada Malika de Caos (2001) o la desafortunada Lilja de Lija-4ever (2002) todas ellas han crecido o bien sin madre, sin padre o bien en un entorno hostil en el cual se han visto desamparadas y sin más posibilidad que dedicarse a la prostitución para sobrevivir. Algunas han heredado el oficio de sus madres, según cuenta la pícara Irma de Irma la Dulce (1963) o la preciosa Violet de La pequeña (1977).

La mayor parte de las prostitutas cinematográficas, pues, no han elegido libremente la prostitución, y casi todas ellas se avergüenzan de la actividad que desempeñan. Y ni que decir tiene que muchas de ellas acaban mal, o bien por enfermedad, suicidándose o asesinadas. Es la prostituta trágica.

De hecho la prostitución es uno de las actividades más peligrosas del mundo, y no es infrecuente que en la mayor parte de las películas sean objeto de malos tratos, de violaciones, palizas, vejaciones varias o a la postre asesinadas: Lulú de La Caja de Pandora (1929), otra Lulú la de La chienne (1931), la Evelyne de Suprema decisión (1939), la Myra, de El puente de Waterloo (1940), la Katty de Scarlet Street (1945) (versión americana de La chienne francesa); Betty y Emy Lou de Una mujer marcada (1937), la María de Troctacalles (1951), la Debby de Sobornados (1953), Nana (1955), la Yvette En cas de malheur (1958), la Gloria de Butterflied 8 (1960) la Nadia de Rocco y sus hermanos (1960), la protagonista innombrada de La commare seca (1962), la Hallie de La gata negra (1962) o la aparentemente libérrima Nana de Vivre sa vie (1962), la enigmática Bilbao (1978), la Colombiana de Pantaleón y las visitadoras (2000) así como la bella Rosario Tijeras (2005), todas ellas mueren o bien asesinadas o bien porque no pudiendo soportar más la situación se suicidan. En muchísimas otras películas asistimos al asesinato o apaleamiento de prostitutas, aunque no sean las 
protagonistas. Por ejemplo, al inicio de Pretty Woman (1990) se produce el asesinato de María la Flaca. En La vida de las marionetas (1981) un burgués con complejos asesina a una prostituta al no poder hacer lo mismo con su mujer. En la cuerda floja (1984) el detonante es el asesinato de varias prostitutas; en Henry, retrato de un asesino (1986) algunas de las mujeres asesinadas son prostitutas; en Enciende mi pasión (1994) se produce una brutal paliza a Ana, la prostituta protagonista, a la que al final mata de un disparo en la cabeza. e Irena en La desconocida (2006) es torturada, violada y apaleada durante escenas de extremo sadismo sexual. Y muchas otras más cuya lista haría interminable este texto. En definitiva, el cine nos ha dado multitud de escenas donde las mujeres prostitutas son violadas, apaleadas, torturadas, quemadas y asesinadas, como si en el hecho de ser prostituta estuviese ya incluido el permiso para maltratarlas. Pareciera que los directores, y los espectadores por persona interpuesta, encontraran más disculpable el maltrato de las prostitutas que el de las mujeres que no lo son; un horror que quedaría amortiguado por el hecho de dedicarse a lo que se dedican, es decir, por ser transgresoras, por haberse situado en el lado oscuro de la vida, por osadas, por desafiar el orden y el papel de sumisas y obedientes que la sociedad les había reservado a las mujeres. Por salirse del camino recto hay que castigarlas, recordando de paso a todas ellas lo que les puede pasar por transgredir las normas sociales y las buenas costumbres.

Si esto tiene correlación con la realidad es algo que se puede discutir, pero no es infrecuente encontrar noticias en las que una prostituta se ha visto envuelta en episodios violentos, o ha sido apaleada o maltratada o incluso asesinada por algún cliente: Detenido un cliente de la joven prostituta asesinada en Gerona (Diario Cordoba, 29-04-2003) o La mujer asesinada en el Eixample era una prostituta de lujo rusa (El País, 10-02-2010) o Detenido por arrojar a una prostituta por el balcón (El País, 17-11-2012). Claro que el cine no es el responsable de la violencia contra las prostitutas, pero los discursos permisivos y recurrentes que se vehiculan a través de los relatos podrían predisponer el ánimo de la ciudadanía a una cierta indulgencia ante este tipo de agresiones, atenuando la gravedad de esta violencia atendiendo a la peligrosidad implícita que conllevaría el ejercicio de la prostitución como actividad marginal tradicionalmente despreciada. 


\subsubsection{La prostituta liberada}

Como hemos visto el cine nos ha dado multitud de ejemplos de la prostituta como una víctima de las circunstancias: mujeres generosas, buenas, entregadas, ingenuas, sencillas, sin maldad, que se han visto inmersas en las redes de la prostitución apenas sin pretenderlo, como una suerte de fatalidad o maldición de la que no han podido escapar. Mujeres que fueron expulsadas del concepto de decencia y que representaron la parte oscura de la vida, aquel reverso del cual era imposible salir, pues la prostitución no era considerada como una situación sino como una condición. Una condición permanente y vitalicia que se arrastraba como una marca indeleble. De ahí títulos ya vistos como mujeres marcadas, marcadas con una mancha que era imposible de borrar.

Sin embargo, y al albur de los tiempos, los discursos cinematográficos también han presentado retratos de mujeres prostitutas por elección. No es casualidad que estas primeras aportaciones se sitúen en torno a los años 60 del siglo XX, cuando empiezan a ganar impulso los movimientos de liberación de las mujeres, las reivindicaciones feministas, la reclamación del derecho a la sexualidad y al uso del propio cuerpo. Es entonces cuando empiezan a resquebrajarse las dicotomías mujer decente/mujer indecente; mujer honesta/ mujer deshonesta. Las mujeres quieren gozar de la sexualidad sin por ello ser consideradas mujeres no respetables. El sexo y la mujer soltera, un libro que aparece en 1962 escrito por Helen Gurley-Brown, precursor de La mística de la feminidad (1963) de Betty Friedan, abrirían las puertas a la idea de que las mujeres no iban a seguir siendo las chicas sumisas eternamente insatisfechas. Que iban a tomar las riendas de sus vidas e iban a construir un nuevo modelo de mujer muy alejado del de esposa y madre complaciente. El feminismo de la primera y segunda ola iba a empezar a expandirse por muchos países y la ebullición de este nuevo movimiento social de emancipación no iba a tardar en verse reflejado en el cine mediante nuevos papeles. Y cómo no, el de la mujer prostituta por elección iba a ser una de las primeras encarnaciones de ese nuevo modelo femenino. Nunca en domingo (1959) presenta a una libérrima Ilia que ejerce de prostituta "cuando y con quien quiere" en el puerto griego de El Pireo. Todos los hombres la adoran, y acaba convertida en líder de un grupo de mujeres que reclaman pisos a precios asequibles para poder ejercer. Claro que al final desaparece en los brazos de un musculoso Tonio, uno de sus muchos enamorados, que la quiere solo para sí. Cuento precursor de una Pretty Woman más modesta que se conforma con un marinero. Jean-Luc Godard, el faro de la 
Nouvelle Vague fue el segundo director que decide presentar una chica que decide ejercer como prostituta libremente, sin coacción ni justificación moral alguna: Vivre sa vie (1962) y Deux ou trois choses que je sais d'elle (1967); en la primera, Nana, una dependienta de una tienda de discos conoce a un tipo que le dice "¿Vamos?" y ella le sigue sin rechistar. Tras una primera vez un poco embarazosa, el proxeneta la adiestrará en la confortable vida de la prostitución, donde "tendrá que aceptar cualquier cliente que pague. Todos, incluidos los asquerosos", según su instructor. Claro que Nana es asesinada al final en un cruce de disparos entre proxenetas que se la disputan, lo cual no es un broche final muy lucido para una actividad que ella ha elegido tan libremente como dejó la tienda de discos donde trabajaba. La segunda, Deux ou trois choses... más enigmática parece un manifiesto anticonsumista donde un par de señoras aburridas parece que se prostituyen por hastío.

Un hito de la prostituta que ejerce sin necesidad lo encontramos en Séverine, la aclamada Belle de Jour (1967) que como muy bien ha explicado Pilar Aguilar, no sabe diferenciar sus deseos fantasiosos de la realidad, y así, mientras el profesor masoquista que acude a que le zurren no abandona su profesión, sino que paga para representar una performance con la que satisfacer sus fantasías, Séverine sí que tiene que ejercer de prostituta en la realidad para satisfacer las suyas. Una diferencia que parece ha pasado desapercibida por todos los estudiosos que han ensalzado la película de Buñel, sin reparar en que Séverine también podría pagar a un apuesto galán para ser humillada durante el tiempo y lugar de su elección, pues satisfacer las fantasías eróticas, sean del tipo que sean, nada tiene que ver con la realidad. Pero al parecer los hombres saben dar curso a sus deseos sin dejar de controlar la situación. Las mujeres tienen que vivir la experiencia pues no saben diferenciar la fantasía de la realidad.

Una de las primeras prostitutas liberadas será la Bree Daniels de Klute (1970) a la que seguirían la Liz Blake de Vestida para matar (1980), la Eva de La mujer flambeada (1983), la Joanna Crane de China Blue (1984), la Lauren Slaughter de La calle de la media luna (1986) o todas las que conforman el piso-liberal de Chicas de Nueva York (1986), la reivindicativa Claudia Draper de Nuts (1987), la afortunada Vivien de Pretty Woman (1990), la tierna Liz de Whore (1991) o la Vassilissa de Mediterráneo (1991). Diez años antes, una renacuaja Iris (Jodie Foster) había oído campanas y no sabía dónde cuando le espeta a Travis: "¿Y qué hay de la liberación de la mujer?", cuando el taxista desquiciado que es 
Robert de Niro se escandaliza al ver a una niña de 12 años haciendo las calles en las cloacas de Nueva York.

Todas las prostitutas de estas películas tienen en común que han decidido ejercer la profesión libremente. $\mathrm{O}$ así lo creen ellas. Todas parecen creer que son libres de utilizar su cuerpo como quieran. La Charo y la Vanessa de Dias contados (1993) son tan ingenuas que ni siquiera tienen conciencia de ser prostitutas: "No digas eso, nosotras no somos prostitutas" dice Vanessa cuando su amiga Charo le dice que su madre, cuando no había dinero en casa, decía que se iba a meter a a puta. Sin embargo, parece que son las únicas que tienen dudas sobre si son putas, pues todo su entorno así las considera. De todas formas, todas estas prostitutas liberadas, sobre las que ya no recae ninguna sanción moral o ética, lo que desean en realidad es que las quieran. A medio camino entre la prostituta liberada y la víctima está Claire Dolan (1998) una joven que debe una importante cantidad de dinero a un proxeneta que no la quiere dejar en paz; y una prostituta que parece controlar su vida es la Jeanne Dielman, 23 Quai du Commerce (1975) una austera y rutinaria ama de casa con un hijo adolescente que recibe algunos hombres en su piso, aunque parece que su equilibrio mental es un tanto precario a juzgar por el final que espera a uno de sus clientes.

A todas ellas les espera un incierto futuro. Bree Daniels encuentra en Klute a su enamorado. China Blue se arriesga a vivir su amor con el suyo. Molly, la protagonista de Chicas en Nueva York parece que no está tan satisfecha de su profesión como ella cree, pues al final la vemos tirar el vestido azul que solía utilizar en el piso-burdel al mismo tiempo que anuncia a Susan, la propietaria: "No voy a volver". Vassilissa se casa con el único hombre que se negaba a ir de putas de todo el batallón. Y de Pretty Woman mejor no hablar, pues ya sabemos que según los relatos cinematográficos encarna el sueño de toda mujer, puta o no: casarse con un millonario guapo que le dé todos los caprichos.

\subsubsection{La prostituta legitimada}

Para que se produzca un cambio en la percepción de los fenómenos sociales deben converger diversos factores: algunos ocurren en el plano de lo real, otros en el plano de lo simbólico. En el caso que nos ocupa, es decir, en la evolución producida en la sociedad a la hora de percibir e interpretar la prostitución han concurrido algunos factores que, aunque sea superficialmente, voy a enumerar. 
No puedo profundizar en el tema tanto como sería deseable por falta de espacio, pero, someramente podemos destacar los siguientes:

a) Cuando se constata que hay prácticas sociales de difícil exterminación pero que atentan contra la salud de la ciudadanía comienza una nueva fase a la hora de abordar esas problemáticas. Es lo que ocurrió a finales de los años 80 en Europa con el nacimiento de una estrategia de actuación que se denominó Harm Reduction Estrategy que consiste en intentar paliar los daños causados por el consumo de drogas, la infección del virus del sida o la propagación de enfermedades de transmisión sexual a través de la prostitución. En un principio esta estrategia de actuación incluía todas las prácticas consideradas de riesgo, aunque poco a poco se ha ido escorando hacia la reducción de daños debida al consumo de drogas. Es una estrategia que no pretende acabar con la práctica en sí, pero sí facilitar la vida de las personas afectadas por esa situación, proporcionándoles información, cuidados, atención sanitaria o cualquier otro tipo de ayuda que pueda beneficiar al individuo, a su familia y a la comunidad. En 2008 hubo en Barcelona un Congreso Internacional sobre Reducción de Daños al cual asistí, y entre los muchos tenderetes que ofrecían información había uno destinado a proporcionar información a las personas en situación de prostitución.

Este es uno de los factores que empezó a influir a la hora de abordar la prostitución. Algunas activistas feministas empezaron a considerar que ante la imposibilidad de acabar con la prostitución lo más adecuado era prestar ayuda a aquellas personas que se encontraran en esta situación, ofreciéndoles asesoramiento jurídico, sanitario, proporcionándoles material preventivo $\mathrm{y}$, sobre todo, comprometiéndose a acabar con el estigma que había acompañado esta práctica ancestral.

b) Un cierto desencanto ante las formas tradicionales de acción política. Ya sea porque las ideologías emancipatorias sufren un retroceso (marxismo, comunismo, anarquismo) ya sea porque los movimientos sociales también se estancan ante la institucionalización de las políticas que antes los animaban. Sucede entonces que los desencantados buscan nuevas formas de activismo político, y vuelven su atención a aquellos sectores marginales menos estructurados y concienciados con los que establecen alianzas y ofrecen colaboración. Ni que decir tiene que estos sectores marginados de población 
reciben la ayuda de esos activistas con interés, pues ven que se preocupan por sus problemas y les proporcionan asesoramiento, a la vez que les dotan de los elementos reflexivos necesarios para otorgar legitimidad a sus demandas. Con frecuencia los activistas tienen la formación teórica y la capacitación profesional suficiente como para servir de consejeros y orientar la acción que les suele faltar a las personas que nunca hubieran pensado en la posibilidad de organizarse para reclamar sus derechos. A título de ejemplo, en 1995 se crea en Madrid el colectivo Hetaira, la primera agrupación de mujeres prostitutas, en alianza con otras que no lo eran y habían militado con anterioridad en partidos del arco extraparlamentario. De ello dan cuenta los telediarios de la época.

c) La aparición de nuevas corrientes de pensamiento que conectan con los nuevos problemas detectados, rescatan las prácticas estigmatizadas del oprobio y las elevan al rango de problema teórico. Este sustrato intelectual acaba de dotar de legitimidad esas situaciones tradicionalmente desprestigiadas y se convierte en la avanzadilla del pensamiento social: es lo que ocurrió con Judit Butler $(1990,2004)$ por ejemplo, y sus teorizaciones sobre la perfomatividad del género, lo queer y la transexualidad; o con algunas aportaciones sobre la prostitución, que ha sido presentada como una lucha contra la opresión, una lucha feminista y una lucha sindical (Peterson, 1992, 2000; Schaffause, 2014). Entre nosotros, las reflexiones de Dolores Juliano $(2002,2004)$ fueron las piedras angulares que cimentaron la nueva manera de enfocar la prostitución.

d) La implantación de un neoliberalismo global

Que pone el foco de la actividad económica en el libre comercio, la globalización de los flujos monetarios, la acentuación de la competitividad, así como la privatización creciente de servicios públicos, la menor intervención del estado en la economía, la desregulación de los mercados con la consiguiente depauperación de las relaciones laborales. En definitiva, el paulatino triunfo del capitalismo más salvaje, que paradójicamente va unido a la defensa a ultranza del individuo como sujeto autónomo y los derechos personales. Focaliza la acción en la capacidad del individuo y menos en los factores de orden social.

e) La entronización del concepto de libertad individual

El neoliberalismo ha encontrado su perfecto correlato en la entronización de la 
libertad individual como motor y centro de toda acción social. El concepto es tan poderoso que actualmente todo es aceptable si se apela a "la libertad de elección individual" (De Miguel, 2015). El concepto de libertad personal domina por encima de cualquier consideración de carácter social, de tal manera que cualquier práctica o actividad es aceptable "si se elige en libertad". Sin embargo, ya Sartre decía que "la libertad es lo que hacemos con lo que han hecho de nosotros", es decir, que no contemplar que la libertad está siempre condicionada por las situaciones previas que nos han precedido y por todo el entramado sociocultural en el que nos desarrollamos es creer que la libertad es absoluta, cuando sabemos que la libertad siempre es relativa. Por otra parte, aunque la libertad individual es un bien precioso que hay que salvaguardar, no es menos cierto que esta libertad individual puede chocar a veces con valores éticos colectivamente defendidos. No siempre las acciones que emprendemos son libres, pues esa libertad hay que contemplarla inserta en una maraña de preceptos, normas y valores que hemos interiorizado, en un entramado de disposiciones, algunas reales (estructuras económicas, sociales, políticas) otras simbólicas (dispositivos culturales, valores, creencias) que condicionan nuestra capacidad de elección. Sin embargo, todos estos condicionamientos parecen desaparecer como por ensalmo en la sociedad actual, y así hemos llegado a la situación de situar por encima de toda consideración la libre elección sin entrar a valorar todos los condicionantes implícitos que tal elección conlleva: si preguntamos a una prostituta de carretera si está allí voluntariamente y por elección propia lo más probable es que nos responda que sí. ¿Podríamos esperar que nos dijera que no? Sin embargo, ¿hasta donde llega su capacidad de elegir y dónde los condicionantes que la han empujado a exponerse en esa situación?

He querido extenderme un poco en las consideraciones anteriores para poder situar en un contexto amplio el tema que nos ocupa, pues la percepción social de la prostitución no puede estar disociada de la percepción de otros fenómenos en los que la sociedad actual se debate, y que implica tanto los derechos individuales como los colectivos.

En el tema que nos ocupa se han impuesto dos visiones del fenómeno: la prostitución forzada, unánimemente condenada por todos los agentes sociales, y la prostitución como elección, sostenida como hemos visto en la capacidad individual de elegir. $\mathrm{Y}$ esta es una disyuntiva que también se traslada, como no podía ser de otra manera, a los productos culturales, y entre ellos, a los relatos cinematográficos y televisivos. 


\subsubsection{La prostituta libre frente a la esclava}

El cine se nutre de la realidad, y la realidad queda representada en las diversas propuestas cinematográficas en un bucle que se retroalimenta continuamente. Lo simbólico es tan importante para apuntalar nuevas formas de percibir la realidad, como la realidad es transformada al proyectar nuevos modelos de comportamiento. El cine se nutre de la realidad tanto como la realidad se nutre del cine, en una simbiosis en la que ya no se sabe qué fue antes, si la propuesta cinematográfica que propone una nueva mirada de lo real o es lo real lo que inspira los nuevos relatos de ficción.

En cualquier caso, a finales del siglo $\mathrm{XX}$, desaparecida definitivamente la injusta división entre mujeres decentes y deshonestas (aunque queden vestigios en estado de latencia que erupciona de forma esporádica) pareciera que la prostitución tuviera que disminuir, dada la mayor permisividad a la hora de mantener relaciones sexuales y la ausencia de sanción moral o ética para las mujeres, que había sido la principal razón por la cual los hombres debían acudir a las prostitutas para satisfacer sus necesidades. Una sociedad más igualitaria en la que hombres y mujeres pueden establecer relaciones sexuales sin menoscabo de la respetabilidad de ellas debería reducir el consumo de prostitución. Sin embargo, no parece que esto haya sido así. No sólo ha aumentado el recurso de la prostitución tradicional, sino que, además, ha irrumpido con fuerza un nuevo fenómeno internacional: el tráfico de personas con fines de explotación sexual.

El tráfico internacional de personas con fines de explotación sexual se ha convertido en uno de los negocios más execrables y más lucrativos del planeta. Si nos atenemos a las cifras facilitadas por la ONU (2016) del total del tráfico de personas, el $54 \%$ lo es con fines sexuales, el $38 \%$ para trabajo forzado y el $8 \%$ restante para otros fines de explotación. Por lo que respecta al género, las mujeres reclutadas con fines sexuales representaban el $72 \%$, el $20 \%$ son reclutadas para trabajo forzoso y el $8 \%$ restante traficadas para otros usos de explotación. También se observa un incremento importante de tráfico de hombres, aunque en este caso el $85,7 \%$ es reclutado para trabajos forzosos, el $6,8 \%$ para explotación sexual y el 7,5\% para otros usos de explotación. La ONU estima que en Europa hay casi 1.000.000 de mujeres que ejercen la prostitución, de las cuales, según las mismas fuentes, 140.000 habrían sido objeto de trata (1 
de cada 7). La Organización Internacional del Trabajo (OIT) estima que en 2005 el valor total del tráfico de personas ascendió a 32 billones de dólares.

Por lo que respecta a España, no hay cifras concluyentes, aunque el CITCO (Centro de Inteligencia contra el Terrorismo y el Crimen Organizado, 2014) estima en 45.000 el número de mujeres que ejercen la prostitución, habiéndose detectado 13.983 que se encontraban en riesgo de trata de seres humanos y/o explotación sexual. Si esto fuese cierto, significaría que habría en torno a las 30.000 mujeres que ejercerían la prostitución por "libre elección". Una cifra muy alejada de la que se había venido repitiendo durante años, (300.000) que se multiplicaba por 10 y que desde luego no había estado contrastada nunca.

Acorde con esta realidad que hemos visto, también en el cine van a emerger dos formas de representar el fenómeno de la prostitución: aquella que se centra en el tráfico de personas con fines de explotación sexual (la denominada trata), y aquella que aborda la prostitución como una actividad profesional tan digna como cualquier otra, y aparentemente mucho más lucrativa. En no pocas ocasiones se refleja esta actividad con un cierto tono de mistificación, presentándola como una profesión altamente rentable sin ningún tipo de connotación negativa: las prostitutas representadas en la pantalla son jóvenes, bellas, glamurosas libres, influyentes, apreciadas por sus clientes, no tienen contradicciones, no sufren ningún tipo de estigmatización y suelen gozar de un nivel de vida al alcance de muy pocas mujeres, sobre todo de aquellas que se mantienen con un sueldo que a veces ni alcanza el salario mínimo interprofesional. ¿Qué nos está diciendo, por tanto, el cine con esta nueva manera de abordar la prostitución? Veamos.

\subsection{El mercado de mujeres}

El tráfico de mujeres no es desde luego un tema reciente, ya al comienzo del cine se introduce lo que en aquel tiempo se conocía como trata de blancas. Así nació Traffic in Souls (1913) entre las más conocidas, pero no fue la única. Russell Campbell en el libro Marked Women enumera una serie de películas de la era muda que se centraron en lo que se denominó the white slavery. Estas películas fueron: Tenderloin at night (1899), The Downward Path (1900), How they do things on the Bowery (1902), What demoralized de Barber Shop (1901), The Barber's Dee Light (1905), La Femme (1908), las múltiples adaptaciones que se hicieron de la novela Resurrección de Leon Tolstoi, como la de D.W. Grififth 
(1909), Madame X (1909). En Dinamarca, entre 1907 y 1912 se produjeron al menos 6 films sobre la trata de blancas, tales como Den hvide Slavinde (1907), Den hvide Slavehandel (1910) Slavehandelrens Flug (1910) Den hvide Slavehandel II (1911) o Den hvide Slavehandel III (1912) todas ellas producidas por Fotorama o por Nordisk Film y que en esencia contaban la historia de una joven que tras una decepción amorosa caía en las manos de una organización de traficantes en ciudades populosas como Londres o San Petersburgo de cuyas redes tenía que ser rescatada. Más tarde se filmaron The Lure (1914) The Litle Girl Next Door (1916) o Litle Door Sister (1917).

Resulta impactante que casi un siglo después Tráffic in Souls/Tráfico de almas (1913) de George Loane Tucker resulte tan actual: Cuatro chicas de diferente procedencia son secuestradas por grupos dedicados a la trata de blancas. Lorna, que trabaja en una pastelería, resultará embaucada por un seductor que la llevará a un burdel tras emborracharla. Sólo la perseverancia de su hermana Mary con la ayuda de un novio policía podrán liberarla de verse ejerciendo la prostitución contra su voluntad. Vemos a Lorna custodiada por una vigilante, desesperada ante la idea de tener que ejercer tal oficio y resistiéndose a claudicar. Al mismo tiempo, la película muestra las tretas que los "ojeadores" utilizaban para captar a las chicas: dos jóvenes suecas llegan a Ellis Island como inmigrantes, y allí un traficante les ofrecerá trabajo en una falsa agencia de colocación que no es sino la tapadera de un burdel. Al mismo tiempo, otro compinche acude a la estación de ferrocarril a donde llegan chicas campesinas para trabajar en la ciudad, y también intentarán engañarlas indicándole el mismo lugar, si bien la acción de un policía perspicaz logrará salvarlas de ese destino. Sorprende que en épocas tan tempranas fuese tratado un tema que reaparecerá con crudeza, como veremos, un siglo después.

Un caso temprano de tráfico de mujeres para el comercio sexual fue el de Carne Viva (Prime Cut) (1972) en el que un granjero aparentemente modélico y de nombre equívoco, Mary Ann (Gene Hackman) tiene una granja de vacas como tapadera para el tráfico de chicas para la prostitución. Un Lee Marvin en un inusual papel de mafioso que se vuelve bueno (Nick Devlin) logrará poner a salvo a Poppy y Violet, las chicas drogadas que como si fuesen reses esperan desnudas sobre la paja que algún desaprensivo las compre. Nick logrará desmantelar también el criadero donde una carcelera tiene encerradas a numerosas niñas para comerciar con ellas cuando tengan edad suficiente. En 
Gator (1976) también vemos a unas chicas medio drogadas en un club de mala muerte encerradas por un mafioso local, Bama, un antiguo colega al que Burt Reynolds tiene que desenmascarar.

Tráfico de personas, droga y prostitución de la mano, como en Mona Lisa, (1986) aunque Simone, la protagonista, ha logrado salir de la sordidez de King Cross y ahora ejerce en los hoteles de lujo del West End de Londres, Cathy, su amada, está atrapada en las redes de los traficantes que la drogan para manejarla mejor, al igual que a otras muchas chicas a las que apalean y maltratan por capricho, pues los clientes afirmen salir contentos y satisfechos.

Incluso nuestra familiar Gloria (Victoria Abril) de Nadie hablará de nosotras cuando hayamos muerto (1995) escapa a duras penas de una banda de traficantes mexicanos con una libreta de direcciones que la chica se ha traído a Madrid. Por recuperar esa libreta -donde aparecen "tiendas-tapaderas" donde se blanquea dinero procedente de la droga- Gloria está a punto de quedarse coja al serle perforada la rodilla con un taladro para que confiese. Gloria, siguiendo el ejemplo de su suegra, que se mantuvo callada durante los posteriores interrogatorios que se produjeron tras la guerra civil, logrará sobreponerse a sus problemas con el alcohol y mantenerse digna y entera. En la película española La Caja 507, (2002) Mónica parece que es una chica a la que Rafael, el policía corrupto de la Costa del Sol, (José Coronado) ha sacado de prostituta de un club de alterne y ahora la mantiene y le paga un piso. Mónica sufre un trato vejatorio, despreciativo, es considerada como parte de las propiedades de Rafael, sin otra función que cumplir que sus órdenes, satisfacer sus deseos y ser receptora de su agresividad. Raquel, de la Distancia (2006) también es perseguida tanto por la policía como por los corruptos porque creen que sabe dónde escondió su marido, asesinado en la cárcel, algo muy valioso, que no puede ser más que droga o dinero.

Algunas películas recientes muestran muy bien el tema de las mujeres que permanecen esclavas en los prostíbulos o clubs regentados por las mafias a las que se les inyecta heroína para mejor controlarlas, como por ejemplo la MalikaNoemí de Caos (2001) o la Jessica de El beso del dragón (2001) o la espeluznante Promesas del este (2007), donde a pesar de no ser la prostitución el tema central, sí es el desencadenante de la acción, cuando vemos a una adolescente entrar en una farmacia y caer fulminada con una hemorragia que le provocará la muerte 
mientras da a luz a una niña. Tatiana, que así se llama la joven muerta, irá descubriendo en su diario -que lee con sobrecogimiento Anna Ivanovna, encarnada por Naomi Watts -, cómo fue engañada para ir a Londres a trabajar en un bar como cantante, cómo la golpearon hasta sangrar, cómo la violaron y cómo finalmente fue reducida al nivel de esclava sexual en un lugar "en que las ventanas están cerradas, por lo que no puedo ni siquiera lanzarme al vacío". Promesas del este presenta un espeluznante retrato de la mafia rusa en Londres, de las que la prostitución de chicas de las diferentes repúblicas soviéticas es sólo una parte del negocio. Terrible el momento en que para demostrar su hombría Nikolai (un Vigo Mortensen impresionante) tiene que coger al azar a una de las prostitutas (una chica más muerta que viva) y sodomizarla delante de Kyril, el reprimido hijo del jefe Semyon.

Y un entorno mafioso y claustrofóbico intuimos también en los flash-backs que acompañan el desarrollo de la película La desconocida (2006), donde la joven ucraniana de 32 años, Irena, es sometida a las más brutales prácticas sádicas por parte de un tipo que se dedica al tráfico de mujeres con fines sexuales. Al final de esta impactante película descubriremos que la escena inicial donde chicas en tanga y con máscaras blancas posan de tres en tres ante un tipo que las escruta a través de una mirilla, lo que está haciendo es eligiendo a la prostituta-esclava que los compradores elegirán para que sea madre de un bebé que los traficantes venderán al nacer. Con estupor veremos que la chica seleccionada -a las que vemos en algunos momentos siendo transportadas en una furgoneta como ganado, otras veces haciendo la calle $\mathrm{u}$ otras siendo salvajemente torturadas-, harán que deje de tomar precauciones anticonceptivas con la intención de que se quede embarazada. El mafioso se encarga después de todo el proceso hasta que entrega el bebé a los compradores. Irena ha tenido nueve hijos en 12 años.

Aunque es un telefilme de dos capítulos realizado para la televisión, no quiero dejar de consignar aquí Tráfico humano (2005) porque monográficamente se centra en el tráfico de mujeres y niñas para la prostitución. Pretende ser un ambicioso retrato de la mafia internacional, aunque focaliza la acción en la inmensa red que organiza con mano dura un único y astuto traficante, Sergei Karpovich (Robert Carlyle) que extiende sus redes por todo el mundo. Más efectista que dramática, este telefilme peca de ambicioso, con numerosos, espaciados y diversos escenarios donde tienen lugar varias acciones paralelas que difuminan el conjunto, y reduce el problema a la captura de un único 
traficante, detenido el cual el problema queda resuelto y con él salvadas las niñas y jóvenes que hemos visto secuestrar en las más de tres horas que dura la película.

Evelyn (2012) es otra película que plantea el problema de las jóvenes inmigrantes que llegan engañadas con promesas de trabajo y son obligadas a prostituirse, que por cierto entronca con The Immigrant/El sueño de Ellis (2013), que retrata la misma realidad pero de hace un siglo, cuando las chicas europeas huían de los estragos de la I Guerra Mundial y emigraban a Estados Unidos, donde algunas, como la polaca Ewa, se vieron atrapadas en los bajos fondos neoyorkinos de los que no sabemos si podrían o no salir.

\section{PROSTITUCIÓN MASCULINA: ALGUNAS DIFERENCIAS}

El tratamiento que el cine ha hecho de la prostitución masculina no tiene ni punto de comparación con el que ha otorgado a la prostitución femenina. No sólo cuantitativamente el número de películas es muy reducido, sino que la manera cómo los directores o directoras han abordado este aspecto es cualitativamente incomparable. Para empezar, la prostitución masculina no ha sido nunca un fenómeno generalizado en toda época y lugar. En concreto, esta división entre mujeres decentes y deshonestas lo que ha hecho es reglamentar cómo las mujeres tenían que utilizar su sexualidad: el sexo para ellas tenía que desarrollarse dentro de la institución matrimonial, e incluso así destinarse sobre todo a la reproducción y, como mucho, a la satisfacción del deseo de su marido, y secundariamente, al propio. La historia de la sexualidad masculina no puede compararse a la historia de la sexualidad femenina. La de los hombres ha sido una sexualidad dominante, reconocida, que se ha sustentado en algunos presupuestos que hasta hace poco se han considerado irrefutables, como era la necesidad irrefrenable de sexo y la legitimidad de satisfacerlo con una mujer legítima, con una querida o directamente con prostitutas. La prostitución, como hemos visto, nunca ha sido contemplada como problema social (si exceptuamos las obras del japonés Kenji Mizoguchi). Durante toda época y lugar se ha considerado decente, tolerable, deseable, necesario e incluso motivo de orgullo para los hombres tener una vida sexual intensa, tanto dentro del matrimonio como, sobre todo, fuera de él. No existe la palabra ninfómano ni prostituto. Desde el principio se utilizó la palabra gigoló para referirse a aquellos hombres que vivían a costa de mujeres adineradas y solas y en nuestros días se empieza 
a utilizar prostituto o puto, pero que no tienen ni de lejos la carga despreciativa que siempre tuvo en femenino.

Utilizar prostituto para denominar la actividad erótica residual y esporádica que han ejercido los hombres no ha sido sino un recurso muy reciente, y más para referirse al sexo masculino de pago con otros hombres que con mujeres. Las mujeres, salvo excepciones, no han recurrido al pago puntual de sexo, y si lo han hecho ha sido en un contexto mucho más complejo, mucho más elaborado, por decirlo así. Hasta épocas bien recientes, que las mujeres pudieran buscar una relación sexual esporádica, con cualquier hombre, mediante pago, era un exotismo y entraba más bien dentro de las leyendas urbanas que en el campo de la realidad. Según datos del Plan integral de lucha contra la trata de mujeres y niñas con fines de explotación sexual en España el 99,7\% de los demandantes de prostitución son hombres.

Entre otras razones porque la sexualidad femenina, subordinada a la masculina, se ha desarrollado con otros parámetros $\mathrm{y}$ ha estado sometida a otros condicionantes. No es extraño, pues, que hasta épocas recientes en que se empieza a reconocer un deseo femenino autónomo y propio, equiparable al deseo masculino, no haya habido productos culturales que hayan narrado la búsqueda de placer sexual de las mujeres con hombres y menos aún con otras mujeres (y mucho menos aún la búsqueda de sexo pagado). Esto nos dice mucho de en qué consideración ha estado la sexualidad femenina hasta hace poco. Las mujeres han buscado antes que sexo, amor, y la historia de la literatura y el cine está lleno de estas mujeres que se han sacrificado por darlo o por obtenerlo.

El cine no podía dejar de recoger alguno de estos relatos de mujeres que recurren a la compra de sexo y, por mejor decir, amor y compañía, pero abordar esta cuestión, así como la prostitución masculina para hombres requeriría otro artículo de igual extensión que el presente. Así que lo dejaremos para otra ocasión.

\section{CONCLUSIONES}

En definitiva, la prostitución es una práctica social inherente al patriarcado que ha sobrevivido a lo largo del tiempo y parece de difícil extinción. En el plano de 
lo real ha atravesado diferentes etapas históricas en las que ha estado prohibida, perseguida, tolerada y a veces incentivada. La sociedad la acepta como una actividad inevitable y aunque en la actualidad se muestra comprensiva ante su ejercicio voluntario, su práctica aún sigue teniendo el estigma y la consideración de una actividad indeseada para sí, aunque aceptable para los demás. Por otra parte, la condena hacia la prostitución forzosa es unánime, al menos en apariencia.

Por lo que respecta al plano de lo simbólico, el cine también ha reflejado a lo largo de su siglo de existencia esta actividad femenina (solo muy tardíamente se ha fijado en la prostitución masculina) que se ha ido adaptando a los diferentes momentos históricos. En general ha enaltecido la figura de esas mujeres caídas, que se vieron inmersas en una práctica socialmente estigmatizada, a las que con el transcurrir del tiempo ha convertido en trabajadoras sexuales si ejercen por elección propia, o en esclavas si han sido obligadas a ello. Claro que la ficción tiene sus propios mecanismos diferentes al mundo de lo real. Y así, en los relatos cinematográficos todo es mucho más fácil: si se aborda el tráfico de seres humanos con fines sexuales, por muy truculenta que sea la acción, siempre puede ser resuelta satisfactoriamente mediante piruetas de los héroes protagonistas. Por contra, la representación de la prostitución por libre elección se presenta de manera mucho más glamurosa, apetecible, sencilla, sin apenas inconvenientes, fácil y sobre todo muy, muy lucrativa, lo cual es una propuesta legitimadora de una profesión al alcance de cualquier joven que lo desee.

Sin embargo, sabemos que en el mundo de la prostitución que supuestamente se ejerce por propia elección no todo es brillo y esplendor, y el cine no debería edulcorar una dedicación a la que muchas jóvenes podrían estar tentadas de entrar y de la cual es muy difícil de salir indemne.

\section{BIBLIOGRAFÍA}

ADPC (2016). Anàlisi del tractament als mitjans de comunicació del tràfic d'éssers humans amb finalitat d'explotació sexual i de la prostitució. Barcelona: ADPC, Ajuntament de Barcelona. 
Aguilar, P. (1998). Mujer, amor y sexo en el cine español de los 90. Madrid: Fundamentos.

Aguilar, P. (2010). El cine, una mirada cómplice en la violencia contra las mujeres. En Á. de la Concha (coord.), El sustrato cultural de la violencia de género (pp. 241276). Madrid: Síntesis.

Amorós, C. (2005). La gran diferencia y sus pequeñas consecuencias... para las luchas de las mujeres. Madrid: Cátedra.

Arranz, F. (coord., 2010). Cine y género en España. Madrid: Cátedra.

Beauvoir, S. (1977). El segundo sexo. Buenos Aires: Ediciones Siglo XX.

Bosch, E. y Ferrer, MV. (2000). La violencia de género: de cuestión privada a problema social. Phsycosocial intervention, 9 (1).

Butler, J. (2004). Deshacer el género. Barcelona: Paidós.

Butler, J. (1990). El género en disputa. Barcelona: Paidós.

Caballero, M. (ed., 2011). Mujeres de cine. Madrid: Editorial Biblioteca Nueva.

Campbell, R. (2005). Marked Women. Prostitutes and prostitution in the cinema. Madison, Wisconsin: University Wisconsin Press.

CITCO (2015). Plan Integral de lucha contra la trata de mujeres y niñas con fines de explotación sexual (2015-2018). Madrid: Ministerio de Sanidad, Servicios Sociales e Igualdad.

Cobo, R. (2017). La prostitución en el corazón del capitalismo. Madrid: Catarata

De Miguel, A. (2015). Neoliberalismo sexual. El mito de la libre elección. Madrid: Cátedra

Foucault, M. (1978). Historia de la sexualidad. Madrid: Siglo XXI Editores.

Freixas, R. y Bassa, J. (2005). Cine, erotismo y espectáculo. El discreto encanto del sexo en la pantalla. Barcelona: Paidós.

Gallego, J. y Luengo, M. (2014). Periodismo social. Madrid: Síntesis

Gallego, J. (2013). Putas de película. Cien años de prostitución en el cine. Barcelona: Luces de Gálibo.

Gimeno, B. (2012). La prostitución. Aportaciones para un debate abierto. Barcelona: Ediciones Bellaterra.

Juliano, D. (2002). La prostitución. El espejo oscuro. Barcelona: Icaria.

ONU (2016). Global Report on Trafficking in Persons. Washington: Oficina de Naciones Unidas para las Drogas y el Crimen Organizado.

Outshoorn, J. (ed., 2004). The Politics of Prostitution. Women's Movements, Democratics States and the globalisation of sex commerce. Cambridge: Cambridge University Press.

Peterson, G. (1992) Nosotras, las putas. Madrid: Talasa. 
Rodríguez Villoria, M. C. (2015). Factores psicosociales asociados a la prostitución: la percepción social y de las trabajadoras sexuales. Tesis Doctoral. Salamanca: Universidad de Salamanca.

Sánchez, L. y García, L. (2014). Los españoles y la sexualidad en el siglo XXI. Madrid: Centro de Investigaciones Sociológicas

Sangro, P. y Plaza, J (eds., 2010). La representación de las mujeres en cine y televisión. Barcelona: Laertes.

Schaffause, T. (2014). Les luttes des putes. La Fabrique: París. 